\title{
Clinical and epidemiological characteristics of hepatitis C virus- infected people who inject drugs: a Greek descriptive analysis
}

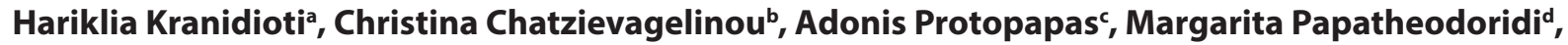 \\ Konstantinos Zisimopoulos ${ }^{e}$, Eftychia Evangelidouf, Pinelopi Antonakaki ${ }^{a}$, John Vlachogiannakos ${ }^{d}$, \\ Christos Triantos ${ }^{\mathrm{e}}$, Ioannis Elefsiniotisf, John Goulisc, Maria Melab, Olga Anagnostou ${ }^{\mathrm{a}}$, Christos Tsoulas ${ }^{\mathrm{g}}$, \\ Melanie Deutsch ${ }^{a}$, George Papatheodoridis ${ }^{d}$, Spilios Manolakopoulos ${ }^{\mathrm{a}, \mathrm{d}}$
}

Hippokration General Hospital, Athens; Evangelismos-Ofthalmiatrion Athinon-Polykliniki Hospitals, Athens; Hippokration General Hospital, Thessaloniki; Laiko General Hospital, Athens; University of Patras; "Agioi Anargyroi" General and Oncology Hospital of Kifissia, Athens; Gilead Sciences, Greece

\begin{abstract}
Background It is estimated that 17,000 people who inject drugs (PWID) in Greece have hepatitis $\mathrm{C}$ virus $(\mathrm{HCV})$ viremia. The aim of our study was to explore the characteristics of the $\mathrm{HCV}$ infected, direct acting antiviral (DAA)-naïve PWID.

Methods This is a retrospective analysis of PWID with HCV infection. We selected data from six liver clinics during the period from $1^{\text {st }}$ May 2014 to $31^{\text {st }}$ May 2017 in order to record the characteristics of infected PWID.

Results We included 800 PWID with HCV infection (78.5\% male, mean age $42 \pm 10$ years) who had not received DAAs before $1^{\text {st }}$ June 2017 . One third of the patients had comorbidities (diabetes mellitus, arterial hypertension and psychological disorders); $70 \%$ were smokers, $27 \%$ alcohol users, $67 \%$ unemployed, $29 \%$ married, and 34\% had education $>12$ years; $65 \%$ were attending addiction programs; $57 \%$ were receiving methadone and $36 \%$ buprenorphine. Sporadic or systemic drug use was reported by $37 \%$ while $1.4 \%$ and $2.9 \%$ had HIV and HBV coinfection, respectively. The genotype distribution was $20.5 \%, 4.6 \%, 3.3 \%, 61 \%$ and $10 \%$ for genotypes $1 \mathrm{a}, 1 \mathrm{~b}, 2,3$ and 4 , respectively. Mean $( \pm \mathrm{SD})$ liver stiffness was $9 \pm 7 \mathrm{kPa}$ and $21 \%$ of the patients had cirrhosis. Half of the patients were in the F0-F1 stage of liver disease, defined as stiffness $\leq 7 \mathrm{kPa}$.
\end{abstract}

Conclusions Our real-life data suggest that HCV genotype 3 remains the predominant genotype among PWID. One third of PWID had comorbidities and one-fifth cirrhosis. Half of PWID had earlystage liver disease and remained without access to DAAs according to the Greek prioritization criteria.

Keywords Hepatitis $\mathrm{C}$ virus infection, people who inject drugs, illicit drug use

Ann Gastroenterol 2018; 31 (5): 1-6

\begin{abstract}
${ }^{\text {a2d }}$ Academic Department of Internal Medicine, Hippokration General Hospital, Athens (Hariklia Kranidioti, Pinelopi Antonakaki, Olga Anagnostou, Melanie Deutsch, Spilios Manolakopoulos); ${ }^{\text {DDepartment }}$ of Gastroenterology, Evangelismos-Opthalmiatrion Athinon-Polykliniki Hospitals, Athens (Christina Chatzievagelinou, Maria Mela); ${ }^{\text {th }}$ Academic Department of Internal Medicine, Hippokration General Hospital, Thessaloniki (Adonis Protopapas, John Goulis); ${ }^{\text {AAcademic Department of }}$ Gastroenterology, Laiko General Hospital, Athens (Margarita Papatheodoridi, John Vlachogiannakos, George Papatheodoridis, Spilios Manolakopoulos); ${ }^{e}$ Department of Gastroenterology, University of Patras (Konstantinos Zisimopoulos, Christos Triantos); “Agioi Anargyroi” General and Oncology Hospital of Kifissia, Athens (Eftychia Evangelidou, Ioannis Elefsiniotis); ${ }^{\mathrm{g}}$ Medical Department, Gilead Sciences (Christos Tsoulas), Greece

Conflict of Interest: Gilead Sciences
\end{abstract}

Correspondence to: Spilios Manolakopoulos, $2^{\text {nd }}$ Academic Department of Internal Medicine, National and Kapodistrian University of Athens, Hippokration General Hospital, 114 Vas. Sofias Ave, Athens 11527, Greece, e-mail: smanolak@med.uoa.gr

Received 5 April 2018; accepted 26 June 2018; published online 19 July 2018

DOI: https://doi.org/10.20524/aog.2018.0293

๑) 2018 Hellenic Society of Gastroenterology

\section{Introduction}

Hepatitis $\mathrm{C}$ virus (HCV) infection is an important public health problem worldwide, with rising morbidity and mortality rates $[1,2]$. Globally, $8-10 \%$ of HCV patients are people who inject drugs (PWID), while drug use is the main mode of HCV acquisition in western populations and an increasing problem for HCV spread in many developing countries $[3,4]$.

The advent of direct acting antivirals (DAAs) has dramatically changed the treatment scenario of $\mathrm{HCV}$ infection. In contrast to the pegylated interferon and ribavirin combination, the standard of care for more than two decades, DAA therapy is noticeably simpler, has significantly fewer side effects, and is much more efficacious, with sustained virological response (SVR) rates reaching 95-99\% [5,6]. This has generated substantial enthusiasm and optimism in both patients and people working in the field of viral hepatitis. Recently, the World Health Organization (WHO) released an ambitious goal targeting HCV elimination by 2030 [7]. 
PWID represent a heterogeneous group consisting of once in a lifetime injectors, recent but not current users, and current users. The interferon era has shown that there are many barriers that prevent PWID form access to diagnosis and treatment. However, anti-HCV therapy under multidisciplinary care has yielded SVR rates similar to those in the non-PWID population, even in those PWID who are active users $[8,9]$. In the DAA era, a prospective study and several post hoc analyses have shown that SVR rates among PWID are comparable to those in non-PWID populations, even in those who are active users or under substitution programs. More importantly, the reinfection rates are relatively low $[10,11]$, while SVR seems to offer not just a virological and personal benefit, but also the prevention of new infections, proving the importance of the unique concept of "treatment as prevention".

In Greece, it is estimated that there were nearly 80,000 people with chronic HCV infection in 2015, while approximately 17,000 current/recent PWID have HCV viremia [12,13]. A mathematical model has shown that, if these patients do not get access to treatment, a substantial increase in the burden of chronic HCV infection will occur in the next 15-20 years [12].

However, as the country was affected by economic crisis, the government has restricted the access to DAA according to the fibrosis stage in order to control the budget impact of such therapies. On the other hand, the Greek government recognized the importance of $\mathrm{HCV}$ infection for public health and joined the WHO declaration for $\mathrm{HCV}$ elimination. Hence, a detailed Hellenic national HCV elimination plan was prepared and released in July 2017. In addition, after comprehensive negotiations between pharmaceutical companies and the Greek National Drug Negotiation Committee, an agreement was reached for lower DAA prices, which resulted in the expansion of the criteria for access to DAA. Thus, since July 2017, patients with moderate to severe liver fibrosis (liver stiffness $\geq 7 \mathrm{kPa}$ ) and all patients (regardless of fibrosis severity) with comorbidities such as chronic renal impairment, HIV coinfection, hemoglobinopathies or hemophilia, organ transplantation or extrahepatic manifestations, can receive DAA therapy.

Since PWID are not currently excluded from the criteria of fibrosis severity for access to DAAs in Greece, a critical question is whether this decision could affect the main target of the national elimination plan, which depends on the proportion of PWID who will remain untreated by such prioritization and will continue to spread the virus. The aim of our study was therefore to explore the epidemiological, virological and clinical characteristics of a large Greek cohort of DAA-naïve PWID with chronic HCV infection, in an attempt to glean further information that may assist the efforts towards $\mathrm{HCV}$ elimination in Greece.

\section{Patients and methods}

This is a descriptive analysis of retrospectively collected data from a cohort of PWID with HCV infection. Six outpatient tertiary liver clinics participated in the study ( 4 in
Athens, 1 in Thessaloniki, and 1 In Patras). For the purposes of this analysis, a PWID was defined as an individual who has a history of past or recent use of injected illicit drugs. We included all consecutive PWID patients who visited the liver clinics during the period from $1^{\text {st }}$ May 2014 until $31^{\text {st }}$ May 2017. Patients who had any experience of DAA treatment during or before this period were excluded. The patients came to the clinics on their own initiative, or via collaboration with addiction programs. We collected patients' demographic and social characteristics, drug use and injection risk behavior, history of HCV diagnostic testing and drug treatment, and selected data regarding serum HCV RNA, HCV genotype, anti-HIV, HBsAg, anti-HBs, anti-HBc. Patients who were active drug users and/or followed opiate substitution programs were considered as a high-risk behavior group. Regarding the drug injection frequency, we considered as systematic users those HCV patients who reported regular drug use, from at least once per week to once per month, and as sporadic users those who reported at least one episode of drug use during the cessation period. Liver stiffness values from transient elastography (TE, FibroScan) were used for fibrosis estimation and staging (Metavir score: F0-F1 no/ mild fibrosis, F2 moderate fibrosis, F3 severe fibrosis, F4 cirrhosis) [14]. The success rate was calculated as the ratio of the number of successful measurements over the total number of acquisitions. The values were expressed in kilopascals $(\mathrm{kPa})$ as the median value of the successful measurements. At least 10 successful measurements, a success rate higher than $60 \%$ and an interquartile ratio less than $30 \%$ were considered reliable and were used in the analysis. All measurements were performed by experienced operators blinded to the patients' clinical information. Liver function tests were used to help diagnose and monitor liver disease or damage, and the Child-Pugh classification was used to grade patients with decompensated cirrhosis [15]. The study was approved by the Ethics Committees of the participating centers and conformed to the principles of the Helsinki Declaration.

\section{Results}

\section{Epidemiological and clinical characteristics}

We enrolled 800 PWID with HCV viremia who visited the outpatient clinics-529 (66\%) from Athens, 141 from Thessaloniki and 130 from Patras-and had available clinical, virological and/or imaging data; the mean age was $42 \pm 10$ years, while most of them $(78.5 \%)$ were male. One third (35\%) of the PWID had received pegylated interferon and ribavirin treatment without achieving SVR. According to the social history, $70 \%$ of the PWID were active smokers, $27 \%$ were alcohol users, $67 \%$ were unemployed, $35 \%$ had education $>12$ years, and $26 \%$ were married. Two hundred forty-one patients (30\%) had comorbidities (diabetes mellitus, hypertension, psychological disorders). HIV antibody was found in $1.4 \%$ and HBsAg in $2.9 \%$ of our cases. Most of the 
patients 537/800 (67\%) underwent TE measurement with a reliable stiffness value. Notably, a minority of patients from Patras had TE data (7/130). The mean liver stiffness was $9 \pm 7 \mathrm{kPa}$ (range: $2.8-44 \mathrm{kPa}$ ). One hundred sixtyeight (21\%) patients had clinical, laboratory, imaging or elastographic evidence of cirrhosis, while two of them also had hepatocellular cancer. Fifty-six (7\%) patients had current or recent evidence of decompensated liver disease (ChildPugh score $>8$ ). Half of the patients (51\%) were in the F0-F1 stage of liver disease (mild fibrosis), defined as stiffness $<7$ $\mathrm{kPa}$ (Table 1).

\section{Risk behavior, substitution therapy and disease stage}

Five hundred twenty patients (65\%) were attending specific addiction programs: $57 \%$ were under opiate substitution therapy (OST) with methadone and 36\% with buprenorphine; the rest of them were attending non-OST programs. Overall, $37 \%$ of our patients reported sporadic $(25 \%)$ or systematic drug use (12\%) (Table 2). Among the PWID, considered as a high-risk behavior group, $42 \%$ had mild liver fibrosis disease (F0-F1) (Table 2).

Three hundred twenty-eight patients diagnosed with HCV before 2005 (group 1) presented significantly more advanced liver fibrosis as assessed by elastography, compared to those diagnosed after 2005 (group 2) (mean TE stiffness: $11 \pm 8.5$ vs. $8 \pm 6 \mathrm{kPa}, \mathrm{P}=0.002$ ). In addition, $35 \%$ of the patients in group 1 had evidence of cirrhosis, compared with $11 \%$ of the patients diagnosed during the last 12 years. More patients in group 1 were treatment-experienced (41\% vs. $29 \%, \mathrm{P}=0.001$ ). Regarding the history of parallel drug use, $30 \%$ of patients in group 1 reported sporadic or systematic drug use, compared to $43 \%$ of those with a recent diagnosis $(\mathrm{P}=0.015)$, No difference in genotype distribution, alcohol consumption or coinfection rates was observed between the 2 groups (Table 3 ).

\section{Virological characteristics}

The genotype distribution was $20.5 \%, 4.6 \%, 3.3 \%, 61 \%$ and $10 \%$ for genotypes $1 \mathrm{a}, 1 \mathrm{~b}, 2,3$ and 4 , respectively, without any significant differences among the participating centers. Mean serum HCV RNA levels were $5.3 \times 10^{6} \pm 3.3 \times 10^{7} \mathrm{IU} / \mathrm{mL}$ and $59 \%$ of the patients with genotype 1a had HCV RNA levels $>800,000 \mathrm{IU} / \mathrm{mL}$ (Fig. 1).

\section{Discussion}

In our study we analyzed real-world data from a sizeable cohort of PWID with HCV infection from 6 referral Greek centers. Our data clearly demonstrated that more than half of our PWID with HCV infection had early-stage liver disease (F0-F1 fibrosis) and therefore do not yet qualify for DAAs
Table 1 Demographic and clinical characteristics of HCV-infected PWID.

HCV infected PWID $(\mathrm{n}=800)$

\begin{tabular}{|c|c|}
\hline Male, n (\%) & $628(78.5 \%)$ \\
\hline Mean age \pm SD years & $42 \pm 10$ \\
\hline $\begin{array}{l}\text { Center } \\
\text { Athens/Thessaloniki/Patras (n, \%) }\end{array}$ & $\begin{array}{c}529(66.1 \%) / 141(17.6 \%) \\
/ 130(16.3 \%)\end{array}$ \\
\hline Unemployed (\%) & $67 \%$ \\
\hline Married (\%) & $26 \%$ \\
\hline $\begin{array}{l}\text { Education } \\
0-6 \text { years } \\
6-12 \text { years } \\
>12 \text { years }\end{array}$ & $\begin{array}{l}16 \% \\
44 \% \\
35 \%\end{array}$ \\
\hline $\begin{array}{l}\text { Failure of previous } \\
\text { treatment (\%) (PegIFN } / \text { / } \\
\text { Ribavirin) }\end{array}$ & $35 \%$ \\
\hline $\begin{array}{l}\text { Comorbidities } \\
\text { (DM, BP, psychiatric disease, } \\
\text { other) }\end{array}$ & $\begin{array}{c}30 \% \\
(2.5 \%, 2 \%, 22.5 \%, 3 \%)\end{array}$ \\
\hline Smoking & $70 \%$ \\
\hline Alcohol & $27 \%$ \\
\hline HBV coinfection & $2.9 \%$ \\
\hline HIV coinfection & $1.4 \%$ \\
\hline $\begin{array}{l}\text { Transient elastography - stiffness, } \\
\text { mean } \pm \mathrm{SD} \text { (range) } \mathrm{kPa}\end{array}$ & $9 \pm 7(2.8-44)$ \\
\hline $\begin{array}{l}\text { Stage of fibrosis } \\
\text { F0-F1 (none/mild fibrosis) } \\
\text { F2 (moderate fibrosis) } \\
\text { F3 (severe fibrosis) } \\
\text { F4 (cirrhosis) } \\
\text { Decompensated cirrhosis }\end{array}$ & $\begin{array}{c}51 \% \\
17 \% \\
11 \% \\
21 \% \\
7 \%\end{array}$ \\
\hline
\end{tabular}

HCV, hepatitis C virus; PWID, people who inject drugs; PegIFNo, pegylated interferon $\alpha ; D M$, diabetes mellitus; $B P$, blood pressure; $H B V$, hepatitis $B$ virus; HIV, human immunodeficiency virus

therapy, according to the national insurance organization criteria for prioritization.

In Greece, as in other western countries, drug usersespecially those with a history of injecting and/or needle sharing-represent the main high-risk group for $\mathrm{HCV}$ infection [16]. A recent report of the Greek Monitoring Centre for Drugs (EKTEPN) has revealed that the prevalence of antiHCV among PWID at the national level is $62.0 \%$, while 17,000 PWIDs are under substitution therapies or may ask for help in the near future [12]. Despite small longitudinal changes, the anti-HCV prevalence has remained stable at the national level over the last 6 years, after a rise that started in 2010, at the same time as the HIV epidemic onset among drug users in the Athens metropolitan area [17,18]. Given that a large proportion of the HCV burden and almost all new HCV cases involve PWID, one might argue that PWID should receive priority for HCV treatment with DAA. Simple mathematical models suggest that high numbers of SVR among cases with a high risk of HCV transmission should be the cornerstone of 
HCV elimination. Moreover, mathematical models predict that elimination is possible in Greece if we increase the number of PWID treated annually [19]. Additional benefits of offering

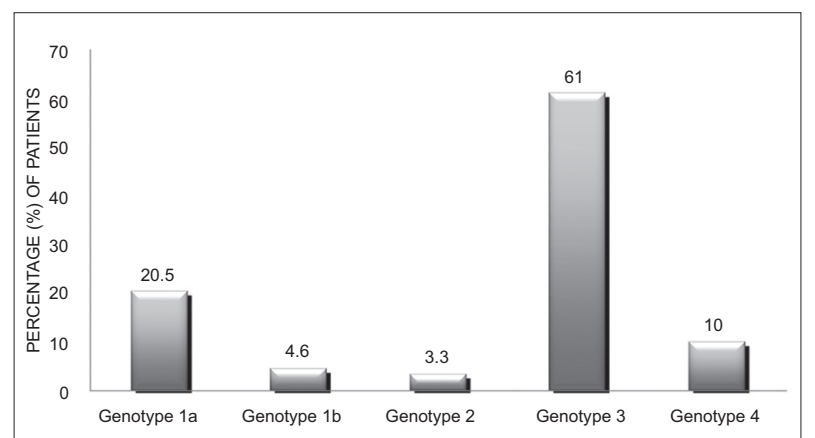

Figure 1 Genotypic distribution of the hepatitis C virus-infected, direct acting antiviral-naïve people who inject drugs $(n=800)$

Table 2 PWID in substitution therapy programs

\begin{tabular}{lc} 
HCV-infected PWID $(\mathrm{n}=800)$ & \\
\hline Substitution program & $65 \%$ \\
Kind of substitution & $57 \%$ \\
$\quad$ Methadone & $36 \%$ \\
Buprenorphine & $7 \%$ \\
Dry program & \\
Parallel drug use & $63 \%$ \\
$\quad$ No & $25 \%$ \\
Sporadic & $12 \%$ \\
Systematic & \\
High-risk behavior group (parallel drug use or/and OST) $(\mathrm{n}=480)$ \\
Stage of fibrosis & $42 \%$ \\
F0-F1 (none/mild fibrosis) & $21 \%$ \\
F2 (moderate fibrosis) & $14 \%$ \\
F3 (severe fibrosis) & $15 \%$ \\
F4 (cirrhosis) & $8 \%$ \\
Decompensated cirrhosis & \\
\hline HCV, hepatitis C virus; PWID, people who inject drugs; OST, opioid \\
substitution therapy
\end{tabular}

access to DAA therapy in PWID include an improvement in histology, a reduction of liver cancer and increased overall survival [20]. Notably, PWIDs who achieve SVR may also have a better quality of life, with an improvement in overall drug use health [21].

According to our data, PWID diagnosed with HCV after 2005 presented with significantly less advanced liver disease compared to those diagnosed before 2005. Given that there was no difference in HCV genotype distribution before and after 2005 [16,22], the above observation may be explained by the fact that patients in the first group are younger and have a shorter duration of chronic HCV infection. Furthermore, almost half of the patients with high-risk behavior, meaning patients with parallel drug use and patients under opiate (methadone/buprenorphine) substitution programs, had mild liver disease. As active drug use is the main route of $\mathrm{HCV}$ transmission in our country, the above finding strongly suggests that the expansion of national insurance organization criteria to include all patients with $\mathrm{HCV}$ is of paramount importance for the elimination of $\mathrm{HCV}$ infection in Greece.

Of the patients receiving OST therapy, $37 \%$ reported active use, while in addition a significant proportion of PWID have never contacted medical or healthcare services. The national plan for HCV elimination should include specific interventions, such as testing, education and linkage, to care for all PWID in order to increase the antiviral treatment uptake; the simplified and efficient DAA treatment should be associated with onsite testing and diagnosis in order to facilitate the HCV care cascade.

We found that one third of the patients had comorbidities, two thirds had a low educational level and $67 \%$ were unemployed. The considerable social and economic disadvantages in association with the stigmatization make the access to health care services for PWID problematic. Given that 10,000 PWID follow OST or dry programs (report of the EKTEPN), the development of community clinics or specific outpatient clinics with a multidisciplinary approach in big cities and mobile one-stop clinics in rural areas may help to overcome the stigma and discrimination and eliminate HCV among PWID within a short period.

Table 3 Differences in PWID according to chronicity of liver disease

\begin{tabular}{|c|c|c|c|}
\hline HCV infected PWID $(n=800)$ & HCV diagnosis before $2005(n=328)$ & HCV diagnosis post $2005(n=472)$ & $\mathrm{P}$ \\
\hline Mean age $\pm S D$ years & $46 \pm 10$ & $40 \pm 10$ & $<0.0001$ \\
\hline Liver stiffness, mean $\pm \mathrm{SD}(\mathrm{kPa})$ & $11 \pm 8.5$ & $8 \pm 6$ & 0.002 \\
\hline Liver cirrhosis & $35 \%$ & $11 \%$ & $<0.0001$ \\
\hline Substitution program & $64 \%$ & $63 \%$ & ns \\
\hline $\begin{array}{l}\text { Kind of substitution } \\
\text { Methadone } \\
\text { Buprenorphine } \\
\text { Dry program }\end{array}$ & $\begin{array}{c}60 \% \\
34 \% \\
6 \%\end{array}$ & $\begin{array}{c}56 \% \\
37 \% \\
7 \%\end{array}$ & ns \\
\hline Parallel drug use & $30 \%$ & $43 \%$ & 0.015 \\
\hline $\begin{array}{l}\text { Treatment experience with } \\
\text { PegIFN } \alpha / \text { ribavirin }\end{array}$ & $41 \%$ & $29 \%$ & 0.001 \\
\hline
\end{tabular}




\section{Summary Box}

\section{What is already known:}

- Hepatitis $\mathrm{C}$ virus (HCV) infection is very common in people who inject drugs (PWID)

- Drug use is the main mode of HCV acquisition in western populations

- The advent of direct acting antivirals (DAAs) has dramatically changed the treatment scenario of HCV infection

- The Greek government has recognized the importance of HCV infection for public health and joined the WHO declaration for HCV elimination

\section{What the new findings are:}

- Half of the PWID with HCV infection had earlystage liver disease, while one fifth of them had evidence of cirrhosis

- One third of the patients had comorbidities, while two thirds had a low educational level and were unemployed

- Genotype 3 is the dominant genotype in Greek PWID

- The majority of the patients belonged to a highrisk behavior group and almost half of them had mild liver disease, thus remaining without access to DAA therapy according to the current Greek prioritization criteria

Interesting findings of this study are the differences in the proportion of PWIDs who attend substitution programs and in the proportion of cases who had undergone elastography among the different centers or cities. For example, in Patras, although there is a well-organized PWID substitution unit, there is no FibroScan available, so patients have to travel in order to have elastography measurements. Thus, consistently with the literature [23], our data revealed that in some settings there is significant lack of coverage of services or barriers when patients try to access services, mainly for geographical reasons.

Another important finding of our study is that 1 of 5 PWID had cirrhosis and one third consumed alcohol. Successful DAA therapy in patients with advanced liver disease is associated with clinical improvement and a decreased risk of progression to decompensation $[24,25]$. Thus, in a country like Greece with a shortage of liver donors, immediate initiation of DDA therapy is of significant importance for these severely ill patients. In addition, clinicians and addiction experts should be aware of the disease stage in order to give the appropriate management guidance for long-term follow up.

Our study has several limitations. The retrospective design did not allow us to obtain more data regarding specific characteristics that may affect future actions for
HCV elimination, such as compliance with visits or high-risk behavior. In addition, the majority of the patients visiting our clinics were selected by expert physicians in addiction programs, so they may represent PWID who are more stable. However, the large number of patients included in the analysis from 6 centers throughout the country minimizes the selection bias and offers a clear view of the characteristics of PWID in Greece.

In conclusion, our study analyzed the current characteristics of a large representative Greek cohort of PWID with HCV infection. The main finding of our study is that half of this population had mild disease based on elastography: they are therefore not yet eligible for DAA therapy, according to the present national prioritizing criteria for treatment. In addition we have shown that comorbidities, and social and economic disadvantages are very common among PWID patients, while they represent the main source for all new cases. In order to accomplish the ambitious plan for HCV elimination, more efforts are needed in order to increase the number of PWID who will start DDA therapy. Immediate expansion of the treatment initiation criteria among high-risk behavior PWID could be the first step in the battle against $\mathrm{HCV}$ in Greece.

\section{References}

1. Stanaway JD, Flaxman AD, Naghavi M, et al. The global burden of viral hepatitis from 1990 to 2013: findings from the Global Burden of Disease Study 2013. Lancet 2016;388:1081-1088.

2. Lavanchy D. Evolving epidemiology of hepatitis C virus. Clin Microbiol Infect 2011;17:107-115.

3. Ly KN, Xing J, Klevens RM, Jiles RB, Ward JW, Holmberg SD. The increasing burden of mortality from viral hepatitis in the United States between 1999 and 2007. Ann Intern Med 2012;156:271-278.

4. Nelson PK, Mathers BM, Cowie B, et al. Global epidemiology of hepatitis B and hepatitis C in people who inject drugs: results of systematic reviews. Lancet 2011;378:571-583.

5. Sulkowski MS, Gardiner DF, Rodriguez-Torres M, et al; AI444040 Study Group. Daclatasvir plus sofosbuvir for previously treated or untreated chronic HCV infection. N Engl J Med 2014;370:211-221.

6. Feld JJ, Kowdley KV, Coakley E, et al. Treatment of HCV with ABT-450/r-ombitasvir and dasabuvir with ribavirin. $N$ Engl J Med 2014;370:1594-1603.

7. Duffell EF, Hedrich D, Mardh O, Mozalevskis A. Towards elimination of hepatitis B and C in European Union and European Economic Area countries: monitoring the World Health Organization's global health sector strategy core indicators and scaling up key interventions. Euro Surveill 2017;22.

8. Manolakopoulos S, Deutsch MJ, Anagnostou O, et al. Substitution treatment or active intravenous drug use should not be contraindications for antiviral treatment in drug users with chronic hepatitis C. Liver Int 2010;30:1454-1460.

9. Elsherif O, Bannan C, Keating S, McKiernan S, Bergin C, Norris S. Outcomes from a large 10 year hepatitis $C$ treatment programme in people who inject drugs: No effect of recent or former injecting drug use on treatment adherence or therapeutic response. PLoS One 2017;12:e0178398.

10. Currie SL, Ryan JC, Tracy D, et al. A prospective study to examine persistent HCV reinfection in injection drug users who have previously cleared the virus. Drug Alcohol Depend 2008;93:148-154.

11. Midgard H, Bjøro B, Mæland A, et al. Hepatitis C reinfection after 
sustained virological response. J Hepatol 2016;64:1020-1026.

12. Hatzakis A, Chulanov V, Gadano AC, et al. The present and future disease burden of hepatitis $\mathrm{C}$ virus (HCV) infections with today's treatment paradigm - volume 2.J Viral Hepat 2015;22 Suppl 1:26-45.

13. Papatheodoridis G, Thomas HC, Golna C, et al. Addressing barriers to the prevention, diagnosis and treatment of hepatitis $\mathrm{B}$ and $\mathrm{C}$ in the face of persisting fiscal constraints in Europe: report from a high level conference. J Viral Hepat 2016;23 Suppl 1:1-12.

14. Mauss S, Pol S, Buti M, et al; European consensus working group on late presentation for Viral Hepatitis Care. Late presentation of chronic viral hepatitis for medical care: a consensus definition. BMC Med 2017; 15:92.

15. Cholongitas E, Senzolo M, Patch D, Shaw S, Hui C, Burroughs AK. Review article: scoring systems for assessing prognosis in critically ill adult cirrhotics. Aliment Pharmacol Ther 2006;24:453-464.

16. Raptopoulou M, Touloumi G, Tzourmakliotis D, et al. Significant epidemiological changes in chronic hepatitis $\mathrm{C}$ infection: results of the nationwide HEPNET-GREECE cohort study. Hippokratia 2011;15:26-31.

17. Sypsa V, Paraskevis D, Malliori M, et al. Homelessness and other risk factors for HIV infection in the current outbreak among injection drug users in Athens, Greece. Am J Public Health 2015;105:196-204.

18. Hatzakis A, Sypsa V, Paraskevis D, et al. Design and baseline findings of a large-scale rapid response to an HIV outbreak in people who inject drugs in Athens, Greece: the ARISTOTLE programme. Addiction 2015;110:1453-1467.
19. Gountas I, Sypsa V, Anagnostou O, et al. Treatment and primary prevention in people who inject drugs for chronic hepatitis $\mathrm{C}$ infection: is elimination possible in a high-prevalence setting? Addiction 2017;112:1290-1299.

20. van der Meer AJ, Veldt BJ, Feld JJ, et al. Association between sustained virological response and all-cause mortality among patients with chronic hepatitis $\mathrm{C}$ and advanced hepatic fibrosis. JAMA 2012;308:2584-2593.

21. Grebely J, Hajarizadeh B, Dore GJ. Direct-acting antiviral agents for HCV infection affecting people who inject drugs. Nat Rev Gastroenterol Hepatol 2017;14:641-651.

22. Savvas SP, Koskinas J, Sinani C, Hadziyannis A, Spanou F, Hadziyannis SJ. Changes in epidemiological patterns of HCV infection and their impact on liver disease over the last 20 years in Greece. J Viral Hepat 2005;12:551-557.

23. Souliotis K, Agapidaki E, Papageorgiou M, Voudouri N, Contiades X. Access to treatment for Hepatitis $\mathrm{C}$ among injection drug users: results from the cross-sectional HOPE IV study. Int J Equity Health 2017;16:101.

24. Smith-Palmer J, Cerri K, Valentine W. Achieving sustained virologic response in hepatitis $C$ : a systematic review of the clinical, economic and quality of life benefits. BMC Infect Dis 2015;15:19.

25. Deterding K, Höner Zu Siederdissen C, Port K, et al. Improvement of liver function parameters in advanced $\mathrm{HCV}$-associated liver cirrhosis by IFN-free antiviral therapies. Aliment Pharmacol Ther 2015;42:889-901. 